\title{
Análise tendencial do discurso de uma ONG
}

\author{
Communication and Information Practice of an NGO Speech quantitative \\ and qualitative analysis
}

Marcia H. T. de Figueredo Lima

Professora do Departamento de Documentação da Universidade Federal Fluminense/RJ.

E-mail: marciahelolima@uol.com.br

\section{Resumo}

A partir das propostas originárias do iluminismo sobre as relações entre informação e cidadania, esta é uma análise das práticas comunicativas de uma Organização Não-Governamental (ONG) no cenário brasileiro a partir da década de 80. Como objeto de estudo foi escolhida a publicação mais importante do IBASE (Instituto Brasileiro de Análise Social e Econômica), o periódico Políticas Governamentais (do número 65 ao 97), por meio da utilização de técnicas bibliométricas. Os parâmetros estatísticos mostraram a palavra democracia como o principal eixo de idéias do IBASE. Indicou também a função do periódico como forma alternativa de fornecer informações, tanto para a mídia como para outros movimentos sociais. Essa pesquisa foi desenvolvida, originalmente, como dissertação de mestrado.

Palavras chave: Organizaçoes não governamentais - Ibase - democracia - cidadania - revista ploíticas governamentais.

A informação, objeto de estudo da Ciência da Informação, muitas vezes assume um caráter eminentemente instrumental-estratégico. Assim, ela pode ser revolucionária ou acomodadora. Pode, em conseqüência, servir a opressores, mas, de vez em quando, alguém se utiliza dela, arma emancipatória, como estratégia de subversão para combater a ortodoxia (ORTIZ, 1983, p. 23).

A informação, nessa sua feição instrumental, está a serviço de alguém, de alguma causa, é instrumento de algum objetivo, de alguma filosofia.

A informação pode servir à construção da igualdade, da cidadania?

Como campo empírico de trabalho, escolhemos uma organização cujo objetivo é democratizar a informação, para, a partir disso, democratizar as instituições, as pessoas, o cotidiano, a sociedade. Isso, num país historicamente construído sob a égide do mercantilismo, do colonialismo, do patriarcado, do domínio e da opressão. Uma organização cujo trabalho partiu justamente da premissa de que "...é preciso colocar tudo em questão" (MOTA, 1984, p.12): da sociedade atual até o nosso passado histórico.

Selecionou-se o IBASE - Instituto Brasileiro de Análises Sociais e Econômicas, considerado a "mãe das ONGs brasileiras". É uma instituição, uma organização não-governamental (ONG) que congrega vários "homens acadêmicos" (BOURDIEU) e cujo objetivo centra-se em trabalhar para movimentos sociais e grupos cujo próprio trabalho vise a emancipação social, a redução das desigualdades, a democracia, o atingir pleno da cidadania.

Visando perceber as tendências discursivas sobre as intenções e metas do Instituto, via suas práticas objetivas de comunicação e informação, escolhemos estudar a "Revista Políticas Governamentais", a principal publicação do Instituto (COTRIN, 1988, p. 12), doravante chamada PG ou simplesmente 
referida como a "Revista",em um recorte retrospectivo de 1991 a 1993 e que cobriu 33 fascículos.

P'rá não dizer que não falei de método

Considerou-se, assim, a "Revista PG", material escolhido para esta análise, como um periódico de acordo com a definição da NB62, isto é:

uma publicação apresentada em fascículos, números ou partes, editada a intervalos pré-fixados, por tempo indeterminado, com a colaboração de diversas pessoas, sob a direção de uma ou várias, em conjunto ou sucessivamente, tratando de assuntos diversos, segundo um plano bem definido (ABNT, NB 62).

Diante da dificuldade de analisar todos os artigos publicados na Revista durante um período específico, devido à variedade de temas tratados, optouse por priorizar uma análise quantitativa.

Dentre inúmeros autores que trabalham a questão da análise de conteúdo, muitos, desde o século passado, tentaram, com sucesso, dar uma abordagem quantitativa à análise do discurso de periódicos (BARDIN, 1991, p 21).

Pela abordagem quantitativa, o que serve como instrumento de análise é a freqüência com que surgem certas características do conteúdo. Utilizando o mesmo material, uma análise qualitativa preocupa-se em detectar a presença e a ausência de uma dada característica de conteúdo ou de um conjunto de características num determinado fragmento de mensagem que é tomado em consideração (BARDIN, 1991, p. 21).

A abordagem quantitativa obtém dados descritivos por meio de um método estatístico. Por garantir certo grau de objetividade, seria útil em uma análise apriorística da Revista. Uma análise qualitativa corresponderia a

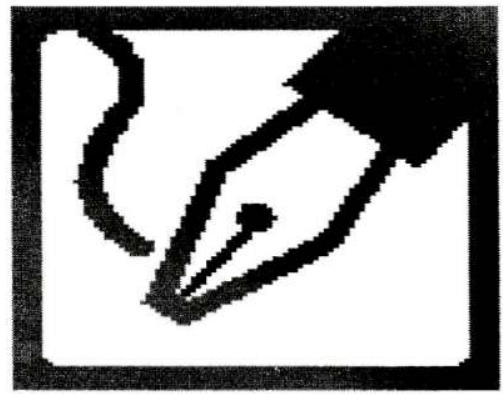

uma análise mais intuitiva, que remeteria aos contextos de geração daquela informação detectada via análise quantitativa. Quais os acontecimentos anteriores ou paralelos às matérias veiculadas? Qual a intencionalidade dos editores ou autores ao valorizar uma palavra $\mathrm{X}$ ou $\mathrm{Y}$ ?

Especificamente no contexto da Ciência da Informação, RIBEIRO, em 1974, fez um estudo aplicando métodos estatísticos à linguagem jornalística. Segundo ela, a linguagem jornalística tem um certo gráu de homogeneidade lexical dentro da sintaxe regular importantíssimo para este trabalho

\section{o estudo desse gênero de discurso sob o ângulo lingüistico, serve de base a análises científicas mais amplas, como o da ideologia de que esse discurso é exteriorização (RIBEIRO, 1974, p. 154).}

Quando se fala em aplicar métodos quantitativos à análise de informação, se fala de Bibliometria, que é a

aplicação de métodos matemáticos e estatísticos a livros e outros meios de comunicação escrita (PRITCHARD, 1969, p. 348-349).

MAIA define Bibliometria como “... o tratamento quantitativo da comunicação escrita" (1973,p. 100) e tem, dentre outros objetivos, o de 
esclarecer os processos de comunicação escrita, da natureza e evolução de uma disciplina (na medida em que essa se manifesta através do conhecimento registrado), por intermédio da contagem e análise de suas diversas facetas (MAIA, 1973, p. 100).

Com a finalidade de analisar um período significativo e abranger a totalidade dos artigos publicados no período delimitado, optou-se por analisar quantitativamente as palavras dos títulos. Nesse sentido, partiu-se do pressuposto de que os títulos dos artigos, sendo a face visível de um discurso, poderiam dizer alguma coisa sobre a intencionalidade do IBASE ou, pelo menos, sobre as idéias que mais interessariam ao Instituto divulgar. Os títulos poderiam, enfim, "desvelar" várias facetas do processo de comunicação privilegiado pelo IBASE. O primeiro redator da Revista, Ricardo Rebouças, justificou essa visão: “Os títulos dizem mais e melhor que um texto..." (REBOUÇAS, 1994, p. 21) disse ele, dissertando sobre a dinâmica da Revista.

Complementando o levantamento quantitativo das palavras dos títulos, contou-se, também, os autores dos artigos com o fim de "ver" quem mais publicava na Revista PG. Correlacionou-se profissões e vinculação institucional dos autores com a produtividade de artigos.

Este estudo teve por meta, enfim, fazer uma "leitura tendencial", isto é, por meio da detecção quantitativa, pretendeu-se "ler" qualitativamente as palavras mais utilizadas e "perceber" quantitativamente a intencionalidade do IBASE, em termos de conceitos e concepções importantes para o Instituto e em termos de profissionais que escreveram para a Revista. Seriam eles especialistas/porta-vozes vinculados ao IBASE, ou o IBASE buscaria experts em outras instituições?
Para este estudo, selecionou-se três anos da Revista - de janeiro de 1991 a dezembro de 1993, dos fascículos 65 a 97, num total de 33 números. Para análise quantitativa, foram computados os títulos de:

- artigos assinados;

- artigos de editoria, isto é, os não assinados;

- entrevistas.

O levantamento de dados foi feito de forma artesanal, sem a utilização de recursos informáticos. Elaborouse um fichário manual. Cada ficha, uma para cada artigo, continha os dados descritivos necessários à análise: título, autor, fascículo, instituições de filiação dos autores, profissão dos articulistas.

Elaboraram-se quadros com a distribuição decrescente de freqüência de palavras e autores.

Geraram-se, também, quadros estabelecendo relações entre a profissão e o número de artigos publicados, e entre a vinculação institucional e o número de artigos produzidos.

Análise das palavras dos títulos

Para tal análise, utilizaram-se as Leis de Zipf e a Fórmula de Transição de Goffman. Tais leis foram elaboradas no âmbito da Lingüística, a partir da observação empírica e da análise de freqüência de palavras em um texto (ZIPF, 1965 citado por MAIA, 1973, p. 100). O princípio "redescoberto" por Zipf foi "o princípio do menor esforço", isto é, uma tendência comportamental na linguagem de se usar muitas vezes um pequeno número de palavras, usualmente monossilábicas e constituídas por pequeno número de letras que constituem o "cimento da língua", por serem palavras de relação (artigos, preposições, conjunções). Da mesma forma, o ser humano tende a usar, na construção de um texto, poucas vezes um grande número de palavras que representam a riqueza vocabular. Esse 
é o princípio de economicidade (ou minimax).

As Leis de Zipf, originalmente elaboradas para textos em língua inglesa, já foram aplicadas em textos científicos e literários brasileiros (PINHEIRO, 1977) e vêm sendo aperfeiçoadas.

Como aplicou-se a metodologia de Zipf para estudar um conjunto de títulos arbitrariamente reunidos, como artifício metodológico considerou-se a Revista PG como um grande "texto" e seus títulos como frases desse "novo" texto construído. Supôs-se, desse modo, que, a despeito de não possuir uma estrutura gramaticalmente "correta" (um texto "real" possui, certamente, muito mais verbos do que esse "artifício"), esse "texto" possuía uma temática interna dotada de lógica, que poderia ser analisada e redescoberta pela análise quantitativa das palavras. Essa temática seria um eixo discursivo do IBASE. Supôs-se, também, que os títulos, tendendo a chamar a atenção do leitor, deveriam conter palavras suficientemente significativas a fim de refletir idéias-chave para a Revista PG e para o IBASE.

Cada título foi decomposto em suas palavras formadoras e cada palavra foi anotada em um segundo fichário, para esse fim.

Os critérios para computação das palavras foram os mesmos adotados por MAIA (1973, p. 102) e MAMFRIM (1991, p. 193).

Com a finalidade de detectar as palavras mais significativas para a Revista, no período estudado, aplicou-se a Fórmula de Transição de Goffman W. Goffman observou, a partir da análise dos trabalhos de Zipf, que em uma lista de distribuição de palavras que ocorrem em um texto, ordenada em ordem decrescente de freqüência, há um ponto onde se dá a transição das palavras de alta frequiência de aparecimento para as de baixa freqüência. Nesse ponto, comumente denominado de ponto $\mathrm{T}$, estão as palavras mais significativas e representativas do conteúdo de um texto.

A Fórmula de Transição de Goffman permite detectar palavras de conteúdo semântico que possibilitam a percepção do discurso de um texto "suficientemente" longo (mais de 1000 palavras). No entanto, como foi elaborada para análise de textos em língua inglesa, tentativas de ajuste matemático vêm sendo feitas para adaptá-la à língua portuguesa. Nesse sentido, trabalharam PINHEIRO (1977) e MAMFRIM (1991).

\section{Análise dos autores}

Todas as matérias que apresentaram indicação de responsabilidade foram computadas para fins de análise dos autores. Desse modo, excluiu-se do universo de análise o que no meio jornalístico convenciona-se chamar de matérias de editoria. Nesse caso, estão usualmente os editoriais e no caso específico da Revista PG, as matérias publicadas na seção Política Global (n. 65 ao n. 79.) e Conjuntura (n. 80 ao n. 97).

Para entrevistas, considerou-se autores os entrevistados - mesmo critério do AACR2 (Regra $\left.2125^{\mathrm{A}}\right)$. Os nomes de tais autores também foram computados como título, uma vez que se lhes dava o mesmo status gráfico usual dados aos títulos.

Foi elaborado um quadro em ordem decrescente de produtividade de autores. A cada autor foi atribuído peso 1 , quer o trabalho fosse individual ou coletivo.

Para analisar a produtividade dos autores, utilizou-se o conceito de Elite, de Price. Solla Price, estudando a produtividade de autores em várias áreas do conhecimento, definiu que em todo grupo de pesquisadores há uma "elite" de autores que publica $50 \%$ do total de trabalhos daquela área. Esse grupo corresponde, geralmente, à raiz quadrada do total de autores, cientistas, pesquisadores detectados. 
Considerou-se, no caso estudado, o grupo de autores que publicou artigos na Revista PG em três anos como uma "comunidade" de trabalhadores intelectuais. $\mathrm{O}$ que se pretendeu "ver" com o resultado propiciado pelo uso do princípio do elitismo de Price foi se havia ou não, no IBASE, o privilégio da Revista PG a autores específicos ou a um tipo de profissional, ou a um sexo.

Após a definição da elite de produtores, redistribuiram-se os autores segundo suas profissões ou formação acadêmica. A coleta procurou limitar-se aos dados constantes na Revista PG, excetuando-se algumas personagens públicas, como Herbert de Souza e Fernando Henrique Cardoso (sociólogos) ou Maria Conceição Tavares (economista e professora universitários). Realizou-se, portanto, um estudo de tendência, uma leitura objetivante da produção de uma ONG. A pergunta que norteou o trabalho sempre remeteu à intenção do IBASE: suas idéias vislumbradas por meio de suas palavras e seus geradores da informação, interlocutores privilegiados neste estudo, por sua maior visibilidade. No outro extremo da cadeia de transferência, somente um olhar bastante pessoal e, por isso mesmo, limitado aos recortes conceituais que foram eleitos previamente, desde o projeto de pesquisa. O posicionamento assumido para a pesquisa foi o de uma assinante de um produto gerado pelo IBASE, quase anônima, já que praticamente não estabelecemos contatos com os dirigentes do Instituto, exceto em duas entrevistas realizadas com pesquisadores do IBASE, na fase exploratória da pesquisa.

"Políticas governamentais", organizações civis e movimentos sociais

A partir da década de 1970 , eclodiu, no mundo inteiro, um tipo especial de organização sem fins lucrativos - as ONGs. A partir da ECO 92, essas entidades passaram a dispensar apresentação mais formal.

Para contextualizar seu surgimento, é apresentada uma classificação das concepções sociológicas que tentam explicar as diferentes formas de organização da sociedade civil, de acordo com a proposta de MOISÉS (1986). Segundo essa visão, são quatro as concepções que norteiam a formação de entidades ou a organização na sociedade civil: concepção associativista, concepção corporativista, concepção estatistaautoritária e concepção movimentalista.

A concepção movimentalista mescla elementos das concepções associativista e corporativista. Baseia-se no robustecimento dos movimentos popular e sindical, às vezes contrapondo-os ao partido político. Gestou a idéia de criar dentro do próprio capitalismo formas de organização anti-capitalistas. Tende a conceber os movimentos, e não os partidos, como canais por excelência da política. Éa partir dessa concepção que se formam os movimentos sociais ou populares em defesa da cidadania, da mulher, do negro, de meninos de rua, da ética na política, de deficientes físicos, de portadores de vírus HIV, contra a fome, de donas de casa, de mães de vítimas do Estado e inúmeros outros.

A literatura vincula as ONGs à concepção movimentalista de organização da sociedade civil, no sentido de que grande parte dessas organizações surgiu com a função de assessoria aos movimentos populares, por considerá-los vetores privilegiados de mudança social.

Uma reflexão importante é que, segundo MOISÉS, no Brasil, sociedade civil significa algo que se contrapõe ao Estado, devido ao autoritarismo das décadas de 1960 e 1970. A partir da abertura, o espaço público que se abriu com a 
redemocratização favoreceu essa visão. As "Diretas Já!" e o "Movimento pela Ética na Política" são dois movimentos que ilustram o quadro analítico proposto por esse autor.

0 lbase, segundo sua auto-visão

O IBASE - Instituto Brasileiro de Análises Sociais e Econômicas, considerado como "a mãe das ONGs brasileiras", apresenta-se como:

\begin{abstract}
uma organização nãogovernamental (ONG) independente, sem fins de lucro, suprapartidária e não religiosa, que se dedica à consultoria $\mathrm{e}$ pesquisa nas áreas de economia, realidade social e política, comunicação e informação (IBASE, 1990).
\end{abstract}

Essa ONG começou a ser gestada no fim do exílio de Herbert de Souza, o último notório exilado a retornar ao Brasil, que se juntou a Carlos Afonso e Marcos Arruda para fundar, em 1981, o Instituto.

O IBASE foi concebido como uma entidade de consultoria, objetivando assessorar movimentos sociais, sempre tendo como meta a democratização da informação, em particular, e da sociedade brasileira como um todo. Instaurou-se no seio da sociedade civil com a idéia de estabelecer um trânsito amplo entre movimentos, partidos e entidades. Estabeleceu como estilo de trabalho a estratégia de congregar esforços com tais grupos, construindo uma ampla rede de comunicação, tanto em nível formal quanto informal. Apresenta-se em suas publicações como:

uma entidade autônoma, comprometida com a defesa dos direitos humanos, com a preservação do meio ambiente, com a justiça, o bem-estar social e, acima de tudo, com a

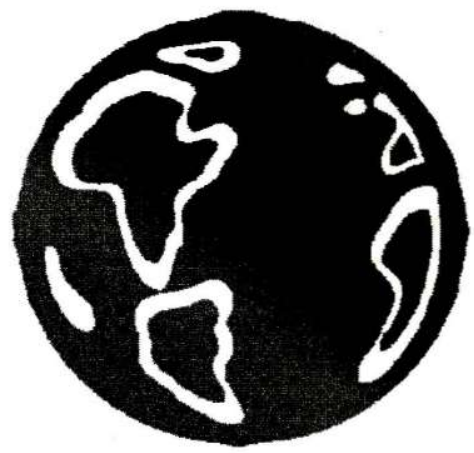

participação de todos os brasileiros na construção da democracia no Brasil (Revista PG, contracapa).

O objeto técnico do IBASE é a informação - "o conhecimento sobre a realidade brasileira analisada sob a ótica da democracia". Seu lema é "democratizar a informação para democratizar a sociedade" e, também, "informar para democratizar a sociedade". Pretende, dessa forma,

contribuir para o fim do monopólio da informação e apresentar a todos os segmentos da sociedade brasileira, principalmente aos movimentos populares organizados, uma visão crítica e alternativa da conjuntura nacional (Revista PG, quarta capa).

Os serviços que pretende prestar dizem respeito à consultoria nas áreas de economia, estatística, comunicação social, estrutura agrária, meio ambiente, sindical e cooperação internacional. Para exercer suas atividades, o Instituto recebe financiamento de mais de 10 países, da própria ONU e, no Brasil, de órgãos financiadores de pesquisa, como a FINEP.

A principal meta do IBASE era assessorar outros grupos, sem substituir ou dirigir qualquer movimento. Era pesquisar, a fim de propiciar dados conjunturais que instrumentalizassem os movimentos populares, prioritária e 
preferencialmente aqueles que pudessem desempenhar um papel fundamental na transformação da sociedade brasileira (IBASE, 1991). Essa auto-visão se alterou nos últimos anos. Internamente, os componentes do Instituto discutiram o papel que o IBASE vem exercendo e o que ele pode realmente vir a exercer, considerando as competências internas que gestou desde sua fundação e o poder social que criou a partir de sua postura comunicacional.

Aos poucos, o Instituto alterava suas posturas. Já no Programa Geral de Atividades para 1990 - 1994 havia uma sinalização para uma busca mais clara e precisa do real papel que poderia exercer. Seria somente assessorar, ou o IBASE já se dava conta de que já era um ator político, stricto sensu?

No próximo item, veremos uma síntese analítica sobre o papel da informação para o IBASE, a partir da fala de um de seus fundadores, Herbert de Souza, e alguns dados obtidos em um entrevista realizada para um trabalho anterior com um dos sociólogos que trabalham no Instituto.

\section{A informação, para o lbase}

Segundo Herbert de Souza (1991), devido à censura imposta aos meios de comunicação de massa entre os anos de 1960 a 1980, a informação, sobretudo na América Latina, transformou-se em sinônimo de poder. Era detida pelo poder econômico (as forças do mercado), sob a censura do Estado (que detém, até hoje, o monopólio da distribuição das concessões de licenças de operação de rádio e TV) e tentava ser apropriada pelos movimentos sociais (pólos organizados da sociedade civil). Data dessa época o surgimento das ONGs.

Para o fortalecimento dos movimentos populares, as estratégias utilizadas, então, foram os contatos diretos, mediante de cursos, seminários, encontros. O Estado, ao mesmo tempo, se impunha, pelo domínio dos meios de comunicação de massa. Note-se, portanto, que era uma micro estratégia, em face do macro e dos mega poderes.

À medida que as elites, livres da tutela militar, voltaram à cena política, os meios de comunicação de massa passaram a ser cruciais para determinar o rumo das eleições, não só as brasileiras, como também, por exemplo, as chilenas e as peruanas. À censura oficial do Estado, sucedeuse a censura empresarial, do "mercado".

Dada a transição entre o autoritarismo ululante e o modelo democrático neo-liberal, a luta política trouxe à tona a questão da formação da opinião pública (consciência coletiva), a qual define o poder do Estado. Para os movimentos populares, a informação é matéria-prima fundamental da ação política, uma vez que legitima o discurso e consegue certo grau de eficácia no confronto entre o poder e os ditos movimentos. É a racionalidade como linguagem instrumental:

O campo da informação, da formação de consciências, é um campo estratégico de luta política pelas transformações ou pela manutenção da ordem. É, em resumo, um elemento estratégico de mudança" (SOUZA, 1991, p. 21).

Mas informação pela informação não basta. Segundo Herbert de Souza, democratizar a informação significa democratizar seu conteúdo e explicitar a democracia como conteúdo central desse processo:

A democracia é que desenvolve o mundo e ela se constrói com e através da comunicação (idem, p. 24).

Daí a necessidade de multiplicidade de centros geradores e 
disseminadores da informação. Às ONGs está destinado o papel de mostrarem a cara em escala nacional.

A maneira de trabalhar do IBASE assemelha-se muito àquela de um centro de pesquisas universitário: elaboram-se projetos, canalizam-se financiamentos de outros órgãos, realizam-se trabalhos de análise documental e trabalhos de campo e disseminam-se as informações, geralmente sob a forma escrita, mas, também, mediante palestras, encontros, seminários, produção de programas radiofônicos, audiovisuais e vídeos que o Instituto coloca à disposição de movimentos populares, associações, sindicatos.

o IBASE trabalha com a pesquisa de dados sobre a realidade sócioeconômica brasileira, buscando não só a análise dos indicadores divulgados pelos organismos oficiais, como também a elaboração de novas informaç̃̃es (Revista PG, contracapa).

Almir Pereira Júnior, em entrevista realizada para um trabalho anterior (SENA et al., 1990), afirmou que o cenário pós-anistia favorecia a autovisão da missão informacional do IBASE como sendo a de prestar uma informação alternativa àquela veiculada pela mídia. A idéia era mostrar "a outra face da moeda". O IBASE utiliza diferentes formas de trabalhar a informação gerada pelas pesquisas que os diversos profissionais realizavam e dirige a cada público os resultados de tais pesquisas, de modos diversificados. Às vezes, o resultado é um livro. Outras vezes, o resultado da pesquisa gera uma série de artigos para o Jornal "O Dia", por exemplo. Em outros momentos, o resultado é uma palestra para uma associação de moradores que tenha encomendado a pesquisa. Ocasionalmente, o resultado pode ser um relatório apresentado ao centro do poder em Brasília.

A meta inicial do IBASE era a de assessorar os movimentos populares. A partir de certo momento, o IBASE passou a portar-se como verdadeiro ator político, criando informações a partir de suas análises e levando-as diretamente ao centro do poder político brasileiro. Foi a partir de informações geradas por outra ONG, por exemplo, que o IBASE desencadeou a Ação da Cidadania contra a Fome e a Miséria e pela Vida. O IBASE deixava, aos poucos, de somente municiar outros movimentos, mostrando seu trabalho, argumentando, ele próprio, com a informação que gerava. O IBASE é hoje uma Instituição tão legitimada que não só trabalha com a geração de uma informação alternativa - como oposta e complementar à majoritária veiculada pela mídia estatuída - mas também porta-voz de movimentos e de outras ONGs similares.

No próximo item, apresentaremos uma contextualização da "Revista Políticas Governamentais", retrato 3 $\mathrm{X} 4$ do IBASE.

\section{A revista "Políticas governamentais"}

O primeiro fascículo da Revista PG foi publicado em maio de 1985 , praticamente quatro anos após a fundação do IBASE. No início, assemelhava-se mais a uma apostila universitária do que a uma revista de circulação comercial. Sem capa, era datilografada, impressa em papel do tipo "ofício", contendo 18 páginas claramente dirigidas a um público restrito de "iniciados". Visava possibilitar uma visão alternativa, fruto de um trabalho "... pioneiro, sistemático e orgânico" (REBOUÇAS, 1994, p. 18). O segundo número veio com o nome "Avaliação Mensal". Assim permanece até março de 1986, quando passa a se chamar "Políticas Governamentais (uma análise crítica)" (sic). Nessa fase, segundo REBOUÇAS, esboçava-se uma metodologia de trabalho: comparar o 
que a sociedade queria ou precisava e o que o Estado efetivamente produzia. Em março de 1986, com a edição do Plano de Estabilização houve o lançamento de um suplemento analítico e, então,

“...consolida-se uma metodologia de análise de conjuntura que compara as demandas sociais com o discurso (promessas) e gestos (atos concretos) dogoverno" (idem, $p$. 19).

Em julho de 1986, passa à tiragem de 1500 exemplares.

No período de análise, manteve a periodicidade mensal. Não é editada no mês de janeiro, todos os anos. Os fascículos, em um total de 11 a cada ano, abrangem períodos que vão da quinzena de um mês até a quinzena de outro: fev/mar, mar/abr, abr/maio, e assim por diante. A tiragem da Revista era, em 1991 (número 65), de 3000 exemplares, e permaneceu inalterada até o número 84 (setembro/ outubro de 1992). A partir do número 85 , a tiragem passou a ser de 3500 exemplares, fruto, talvez, de campanhas para aumento do número de assinantes realizadas pela Revista, para atingir um público maior.

No número 79 , ao fim do editorial, aparece a seguinte nota:

A partir deste número, $P G$ deixa de ser editada por Carlos Castilho e Sônia Guimarães, que passam a exercer novas funções no exterior, noutra ONG também empenhada na luta pela democratização da informação" (PG, n. 79, p. 3 grifo meu).

O número 80 (maio/junho 1992), com o novo editor, Nilo Sérgio Gomes, já começa a mostrar mudanças. Trata-se de uma edição especial dedicada à ECO 92, o que marca o início de uma transição no aspecto visual da Revista.

As seções, antes dedicadas a diferentes facetas de macropolíticas federais nas mais diversas áreas, recebem novos títulos. A seção "Política Orçamentária" passa a ser "Orçamento da União", por exemplo. Simbolicamente, parece, a Revista analisava não mais a política oficial em relacão a um fato, fenômeno, carência ou demanda social. Passava a analisar o fato, $\underline{\mathbf{0}}$ fenômeno, $\underline{\mathbf{a}}$ carência, a demanda, com todas suas implicações históricas e contextuais.

É verdade também que, já no último número de 1991 (novembro/ dezembro), os antigos editores prometiam:

A partir de janeiro/fevereiro do ano que vem, a Revista vai continuar acompanhando o que se passa a nível federal, mas abrirá um espaço especial para as experiências. que se desenvolvem nos estados e municípios. Trata-se de uma das vertentes capazes de dar aos cidadãos a possibilidade de refazer a prática democrática, em bases realmente novas (PG, $\mathrm{n}$. 75, p. 3).

Com o novo editor, os voluntários cedem lugar, cada vez mais, ao corpo profissional do IBASE. O trabalho editorial visa tornar a revista mais atraente $\mathrm{e}$ as entrevistas crescem em importância.

A análise de conjuntura cede lugar a um estilo opinativo mais contundente, em textos mais reflexivos.

Segundo REBOUÇAS, todo mês é feita uma reunião para definir, em grupo, as temáticas mais presentes no noticiário veiculado pelos meios de comunicação de massa e, a partir da percepção conjunta do que está mais presente na memória social em cada momento, é definida a pauta de publicação.

No próximo item, analisaremos os resultados obtidos na coleta de palavras presentes nos títulos e dos autores dos artigos. 


\section{Resultados e discussão}

No período estudado, de fevereiro de 1991 a dezembro de 1993, foram publicados 331 artigos, dos quais 311 traziam títulos e 291 eram assinados por um ou mais autores.

Aplicando-se a Lei de Zipf e a Fórmula de Transição de Goffman, procurou-se detectar as palavras significativas mais utilizadas nos títulos dos artigos pelos autores e editores na Revista, em um período de três anos. Obteve-se, para análise de palavras, um universo de 1.565 palavras, utilizadas no título de 311 artigos. Dessas $1.565,911$ são repetições, o que implica em um percentual de $60 \%$ de repetição, confirmando $o$ princípio de economicidade no uso da língua escrita.

No universo estudado, $80 \%$ das palavras são substantivos, o que, de certa maneira, não configura um texto "normal" em língua padrão culta.

Aparentemente, neste estudo, as palavras de alta freqüência não apresentariam interesse, pois, teoricamente, só seriam encontradas palavras de baixo teor semântico, que não permitiriam inferências sobre as metas editoriais do Instituto. Nossa análise deveria recair, principalmente, sobre as palavras detectadas via utilização da Fórmula de Transição de Goffman.

A seguir, uma lista das palavras analisadas:

DEMOCRACIA - 14 vezes
CRISE - 13 vezes
BRASIL - 11 vezes
GOVERNO - 11 vezes
POLÍTICA - 10 vezes
COLLOR - 10 vezes
CIDADANIA - 9 vezes
FOME - 8 vezes
REVISÃO - 8 vezes

Neste estudo, a palavra DEMOCRACIA apareceu quatorze vezes, junto às palavras de alta freqüência. Recontextualizada, está ligada aos mais variados temas: VIOLÊNCIA, IMPACTO AMBIENTAL, MÍDIA, INTERNACIONAL.

Isso significa que o tema (não só a palavra) DEMOCRACIA é tão importante para o IBASE que está, analogamente, posicionada com aquilo que "cimenta" a informação por ele gerada e até com a própria existência do Instituto. Democracia é a idéia-chave do IBASE, está explicitada como forma e conteúdo. Coerência manifesta entre objetivos e o fazer cotidiano, está presente no lema do Instituto - "informar para democratizar" e ocorre, também, em formas derivadas de palavras de menor freqüência, como: DEMOCRÁTICA, DEMOCRATIZANDO, DEMOCRATIZAÇÃ®. Homeopatia ou "catequese"?

Pouca diferença há entre a utilização da palavra DEMOCRACIA em artigos assinados ou de editoria. Isso pode significar não só a premência do tema para o Instituto, através do espaço dos editores, como porta-vozes do IBASE, como também a consciência da temática para os colaboradores como indivíduos. Sujeitos que constróem a democracia, utilizando o cimento institucional ideacional do IBASE.

As demais palavras, no relatório completo desta pesquisa, refletiram situações conjuntarais como a campanha pelo impeachment de Collor (Crise e Collor), a preparação da revisão constitucional, a campanha contra a fome da Ação pela Cidadania, levada pelo próprio IBASE.

Quanto aos autores, os números demonstram que a equipe é interdisciplinar, mas os economistas lideram o ranking de publicação, com 86 trabalhos $(26,7 \%$ dos trabalhos assinados). São economistas com preocupações sociais que, talvez, ou por isso mesmo, privilegiam o espaço 
de uma ONG para propor soluções alternativas mais globalizantes que os estreitos discursos "economicistas".

Também há de se pensar se os economistas não representariam, para o IBASE, a feição instrumentalestratégica do seu trabalho, isto é, os economistas seriam instrumentos que permitiriam confrontos de igual para igual entre a ortodoxia e uma proposta alternativa de sociedade mais igualitária. Já que o discurso privilegiado nas esferas governamentais e da mídia é o da racionalidade instrumental econômica, parece que o Instituto optou por confrontar-se, dialeticamente, com esses poderes, mediante um discurso que lança mão da mesma lógica legitimada por tais poderes estatuídos.

Evidentemente, ao comparar-se a tiragem de uma revista semanal como "Isto É", por exemplo, pareceria demasiada credulidade acreditar no "poder de fogo" de 3.500 exemplares contra mais de 420.000 . Resta trazer o quadro conceitual à tona para pensar que existe uma previsibilidade do micropoder informacional, da microestratégia de falar a poucos e selecionados interlocutores, ganhar espaço entre pessoas capazes de catalisar socialmente mudanças de opinião, entre outros. Poderíamos tentar uma analogia: essa microestratégia lembra uma "guerrilha" e nos remete ao quadro conceitual da origem dos membros das ONGs brasileiras (Igreja, meio universitário e partidos clandestinos de esquerda dos anos 1970), que visariam, agora, batalhar por uma sociedade mais justa, esgrimando com palavras.

Como não nos detivemos nos assinantes da Revista, resta aí uma lacuna a estudar posteriormente, que consiste em pensar a eficácia simbólica de tal estratégia: quem lê a Revista PG? Como o saber ali construído é utilizado e repassado?

Outro dado interessante é que os professores universitários, que apresentaram um total de 33 artigos, em uma média de um artigo por autor, talvez encontrem, também, um espaço alternativo para proporem soluções mais socialmente "engajadas" do que permite o trabalho intramuros universitários. Esse dado confirma, também, a teoria sobre a simbiose entre Universidade e ONGs.

Quanto à vinculação partidária, também foi privilegiado o espaço aos partidos mais progressistas, à esquerda brasileira, na época representada pelo PDT e pelo PT.

Poder-se-ia dizer que, talvez, as ONGs dêem vazão a um represamento das idéias políticas da esquerda e, por isso, se configurem como alternativas. Do mesmo modo, a presença dos representantes da Universidade pode ser assim explicada. Esses espaços, somados à Igreja progressista, aliás, são os fundadores das ONGs no quadro brasileiro.

Quanto à questão religiosa, privilegiou-se o espaço da Igreja Católica, sobretudo do clero fortemente ligado à questão fundiária.

Interessante observar-se, também, que a postura do IBASE volta-se mais para um sindicalismo que visa a promoção social do trabalhador com conquistas lentas, mas efetivas e desconsidera-se o chamado "sindicalismo de resultados". Nesse contexto, ganha espaço a CUT, enquanto a CGT praticamente não aparece.

\section{Conclusão}

Certamente, quando um Instituto se propõe a trabalhar publicando uma Revista, não é o paradigma participativo que permeia esse trabalho, mas o paradigma difusionista. Assim, com a Revista PG o IBASE visa difundir suas idéias a um público pequeno, que talvez atinja 10.000 pessoas (uma média aproximada de três leitores por fascículo, circulante mensalmente). 
Arriscamo-nos a inferir que esse seja um público seleto, capaz de entender a linguagem dos diferentes tipos de bacharéis que trabalham para a Revista.

Tais bacharéis são pessoas preocupadas em trazer à cena da discussão visões alternativas (porque diferentes) e mais globalizantes (porque dialéticas e contextualizadas) dos temas veiculados pela grande imprensa.

Por que os economistas, e não os sociólogos, são a maioria? Simbolicamente, talvez porque os primeiros sejam os maiores representantes da racionalidade no nosso tempo. Ou, mais concretamente, porque permitiriam o embate discursivo em face dos economistas oficiais (quer do Estado, quer da mídia) de plantão.

O que se intentava mostrar e, em um certo sentido, foi possível, é que as palavras, veículos das idéias, têm a sua força.

As mesmas palavras, dependendo do estilo com que sejam arrumadas, podem falar da crise de democracia, da construção da cidadania e da necessidade de inclusão dos descamisados, via fim da fome e conquista da dignidade do trabalho. Metas ambiciosas em um país no qual, devido à tradição autoritária, não se vive sem a tutela do governo (tão forte que se confunde com o Estado, no imaginário popular).

$O$ período de análise marcava as vésperas do século XXI, e o Brasil era, ainda ali, um país que se debatia entre a ética da solidariedade e a ótica do autoritarismo. A via apontada por essas palavras foi a da convivência negociada de cidadãos emancipados, em que pese a necessidade premente de uma reformulação "desentoxicante" da formação histórica que nos legou um apartheid pior que aquele da África do Sul, porque não assumido.

"Essa mudança não corre, mas ocorre", nos diziam as palavras do
IBASE. Era uma mudança que ocorria no seio da sociedade civil, redescoberta com a "redemocracia". Era uma mudança que se gestava na indignação contra o autoritarismo e ressurgia da solidariedade entre "subversivos", religiosos e "doutores", que dantes não se misturavam, "ateus" $\mathrm{e}$ guerrilheiros, e homens de batinas ou becas. Uma solidariedade que reunia homens que manejavam espingardas com outros que trabalhavam com batutas ou erguiam cálices e se perguntavam se Deus era realmente brasileiro.

Essas palavras nos informavam sobre um terceiro caminho, longe da força do Estado ou do poder do mercado, baseado mais em relações interpessoais locais e, por isso, mais próximas, gerido por micropoderes que estavam sendo criados ao andar. Era um caminho tortuoso, humano e sujeito, algumas vezes, a resvalos na própria ética de subordinar fins justos a meios oriundos do financiamento do próprio Estado e de fundações dantes ditas imperialistas...(FINEP, no primeiro caso, e Fundação Rockfeller, no segundo).

Essas palavras veiculavam uma informação que visava gerar uma percepção daquilo que seria uma sociedade mais democrática e cidadã. Essa informação - estratégica, racionalista, instrumental - vinha de uma simbiose entre vários tipos de saber e pôde, ela mesma, ser catalisadora de novos saberes que visavam construir uma sociedade na qual a democracia e a cidadania fossem tão corriqueiras que não mais seria necessário falar sobre elas. Todo discurso afirmativo em prol de uma causa denota a falta daquilo que se enuncia.

E, por fim, trazendo a própria palavra do Instituto, REBOUÇAS, o primeiro redator da Revista PG, avalia: 
a questão democrática é o eixo explícito do IBASE e da própria $P G$ “..." $O$ fio condutor dos tempos vividos é a governabilidade e o processo democrático'. O percurso da PG, que evolui da denúncia para a proposta é a forma de atuor nesta fase. Caminho dificil pelo qual poucos se arriscam. A ética, a cidadania e a democracia terão de passar de palavras para gestos

O IBASE seria, assim, definido pela idéia de democracia: difundir democracia, gerar democracia, discutir democracia.

Post-scriptum

Esta leitura tendencial que se realizou sobre as palavras do IBASE explicitou a coerência entre metas $\mathrm{e}$ discurso do Instituto.

A palavra mais importante durante o período estudado foi DEMOCRACIA, detectada mediante simples enumeração de freqüência das palavras dos títulos. Essa palavra-idéia-emblema foi tão importante que ocorreu junto com artigos, conjunções e preposições em termos de freqüência. Ela foi tão importante que, no número 100 , quando já havíamos encerrado este trabalho, o título da Revista mudou para... DEMOCRACIA.

Precisa dizer alguma coisa mais?

\section{Abstract}

Starting from illuminist proposals about the relationship between citizenship and information, they analyze the communication and information practices of an NGO (Non Governmental Organization) in the Brazilian scenario from the 80 's on, as a generator/transmitter of information, relating its arising within the reborn civilian society after the end of the dictatorship period. As an empirical field of study, selects IBASE (Brazilian Institute of Social and
Economical Analysis) - mother of all Brazilian NGOs - that is analyzed through its main publication - the periodical "Políticas Governamentais" (from number 65 to 97 ) - from which they try to perceive a biased reading of the speech in quantitative and qualitative terms, through the words used in the titles of the published topics, by means of bibliometric techniques and a quick summary of its authors, in terms of gender, academic background and institutional entailing. The conclusion, within the statistical parameters, showed the word democracy as the main set of ideas of IBASE. They also outline an attempt of analysis as far as the function of the periodical, as it is said, targeting the formation of social movement leaderships and its roll as an alternative mean of communication to the official information and the media. The title of the periodical, starting from number 100 is DEMOCRACIA (Democracy), what validated the perception of statistical reading. Originally this research was developed as a Master's Information Science dissertation.

Keywords: non governmental organizations - Ibase (Brazilian Institute of Social and Economical Analysis) - Democracy (Brazil) Citzenship (Brazil) - Governmental Policies (periodical)

\section{Referência}

ASSOCIAÇÃO BRASILEIRA DE NORMAS TÉCNICAS. Apresentação de publicações periódicas. Rio de Janeiro : ABNT, 1978. (NBR62)

BARDIN, Laurence. Análise de conteúdo Lisboa: Edições 70, 1991, c1977.

BOURDIEU, Pierre. Sociologia. São Paulo : Ática, 1983.

CASTORIADIS, Cornelius. O imaginário e a criação no domínio social-histórico. In: . As encruzilhadas do labirinto 2 : os domínios do homem. Rio de Janeiro : Paz e Terra, 1987. p. 225-244. (Coleção Rumos da Cultura Moderna, 54)

CASTORIADIS, Cornelius. A polis 
grega e a criação da democracia. In: As encruzilhadas do

labirinto 2 : os domínios do homem. Rio de Janeiro : Paz e Terra, 1987. p. 268-313.

CASTORIADIS, Cornelius. Reflexões sobre o desenvolvimento e a "racionalidade". In : . As encruzilhadas do labirinto 2 : os domínios do homem. Rio de Janeiro : Paz e Terra, 1987. p. 135-158. (Coleção Rumos da Cultura Moderna, 54)

CCAA2. Código de catalogação Anglo-Americano. São Paulo : FEBAB, 1985, v. 2, p. 44. Regra $21.25^{\mathrm{A}}$

CEBOTAREV, Eleanora. Novas ferramentas para a comunicação intercultural : pesquisa participativa e tecnologia apropriada. Viçosa : UFV, 1983. $20 \mathrm{p}$.

DURHAM, Eunice. Movimentos sociais : a construção da cidadania. Novos Estudos CEBRAP, São Paulo, n. 10 , p. 24-30, out. 1984.

FERNANDES, Geni Chaves. O que é a Ciência da Informação : identificação através de relações conceituais entre 3 visőes. Rio de Janeiro, 1993. 164 p. Dissertação de Mestrado em Ciência da Informação, convênio CNPq/IBICT e UFRJ/ECO. FERNANDES, Rubem César. Sem fins lucrativos. In: LANDIN, Leilah, org. Sem fins lucrativos : as organizações não-governamentais no Brasil. Rio de Janeiro : Instituto de Estudos da Religião, 1988. p. 8-23. (Cadernos do ISER, 20)

FERNANDES, Rubem César; CARNEIRO, Leandro Piquet. ONG anos 90 : a opinião dos dirigentes brasileiros. Rio de Janeiro : ISER, Núcleo de Pesquisa, 1991.42 p. (Série Textos de Pesquisa, 1)

FÓRUM GLOBAL 92 (1992 : Rio de Janeiro). Calendário oficial. Rio de Janeiro, 1992. p. 146-167.

FREIRE, Paulo. Pedagogia da esperança : um reencontro com a pedagogia do oprimido. 2. ed. São Paulo: Paz e Terra, 1993. p. 9-50. GONZÁLEZ DE GOMEZ, Maria Nélida. Informação, inovação e democratização: a transferência de conhecimento e o movimento associativo. Rio de Janeiro, 1992. 2 v. Tese de Doutorado em Comunicação pela UFRJ, Escola de Comunicação. GONZÁLEZ DE GOMEZ, Maria Nélida. O objeto de estudo da Ciência da Informação : paradoxos e desafios. Ciência da Informação, Brasília, v. 19, n. 2, p. 117-122, jul./dez. 1990. GONZÁLEZ DE GOMEZ, Maria Nélida. O papel do conhecimento e da informação nas formações políticas ocidentais. Ciência da Informação, Brasília, v. 16, n. 2, p. 157-167, jul./ dez. 1987

GRAMSCI, Antônio. A formação dos intelectuais. In : . Os

intelectuais e a organização da cultura. 4. ed. Rio de Janeiro : Civilização Brasileira, 1982. p.3-23. HABERMAS, Jurgen. Consciência moral e agir comunicativo. Rio de Janeiro : Tempo Brasileiro, 1983. Ciências sociais reconstrutivas versus ciências sociais compreensivas, p. 37 60.

HABERMAS, Jurgen. Técnica e ciência enquanto ideologia. In: BENJAMIN, Walter et alii. Textos escolhidos. 2. ed. São Paulo : Abril Cultural, 1983. p. 313-343. (Coleção os Pensadores)

IBASE : análise e informação a serviço dos movimentos populares. Perspectiva Universitária, p. 3-8, 1990.

IBASE. Ibase 10 anos : nota 10 para a democracia. Rio de Janeiro, 1991.

IBASE Programa geral de atividades : 1990-1994. Rio de Janeiro, 1990.

MACHLUP, Fritz. Semantic quirks in studies of information. In : MACHLUP, Fritz, MANSFIELD, Una, (eds). The study of infomation. New York : J. Wiley, 1983. p. 660-661.

MACHLUP, Fritz; MANSFIELD, Una. Cultural diversity in studies of information. In : , (eds).

The study of information. New York : J. Wiley, 1983. p. 27-29.

MAIA, Elza de Lima e Silva. Comportamento bibliométrico da língua portuguesa como veículo de representação da informação. Ciência da Informação, Rio de Janeiro, v. 2, 


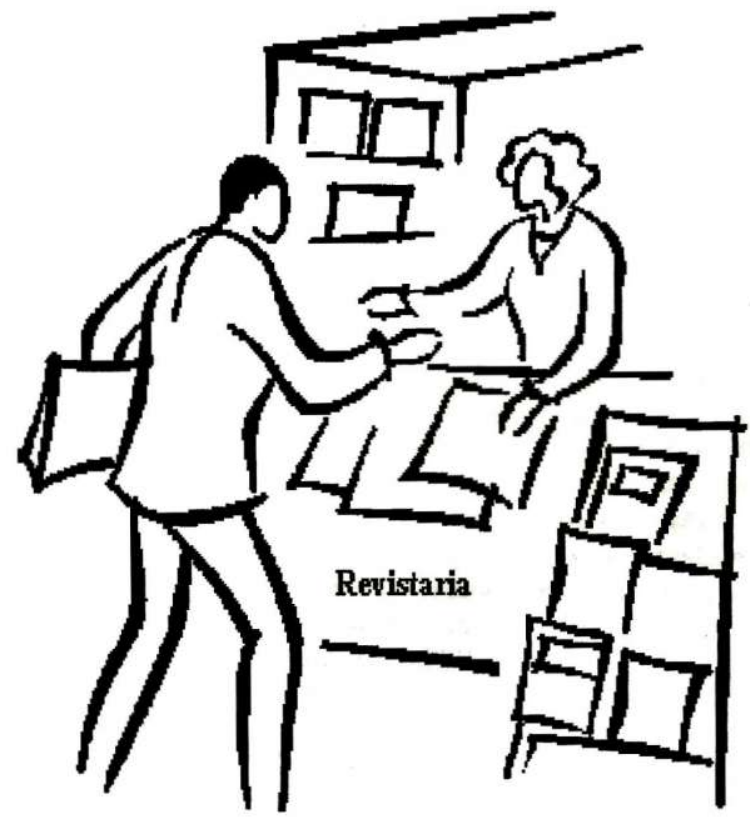

n. 2, p. 88-138, 1973.

MAMFRIM, Flávia Pereira Braga. Representação do conteúdo via indexação automática em textos integrais em língua portuguesa. Ciência da Informação, Brasília, v. 20, n. 2, p. 191-203, jul./dez 1991.

MARTELETO, Regina Maria. Informação : elemento regulador de sistemas, fator de mudança social ou fenômeno pós-moderno? Ciência da Informação, Brasília, v. 16, n. 2, p. 169-180, jul./dez. 1987.

MOISÉS, José Álvaro. Sociedade civil, cultura política e democracia : descaminhos da transição política. In: COVRE, M. L. M., org. A cidadania que não temos. São Paulo : Brasiliense, 1986. p. 119-150.

MOTA, Carlos Guilherme. Nota introdutória. In: org. Brasil em perspectiva. 14. ed. São Paulo : DIFEL, 1984. p. 12. (Coleção Corpo e Alma do Brasil, v. 23)

ORTIZ, Renato. Introdução : à procura de uma sociologia da prática. In: BOURDIEU, Pierre. Sociologia. São Paulo : Ática, 1983.

PINHEIRO, Lena Vânia Ribeiro. Estudo bibliométrico em linguagem literária. Rio de Janeiro, 1977. 17 f.
Monografia apresentada ao Curso Sistemas de Recuperação da Informação, Professora Gilda Maria Braga. Mestrado em Ciência da Informação - IBICT.

POLÍTICAS GOVERNAMENTAIS, Rio de Janeiro, IBASE, n. 65-97, fev./ mar. 1991-nov./dez. 1993.

PRITCHARD, A. Statistical bibliography or bibliometrics? Journal of Documentation, v. 25 , n. 4 , p. 348349, Dec. 1969

REBOUÇAS, Ricardo. PG : 100 edições em defesa da democracia. Políticas Governamentais, Rio de Janeiro, v. 10, n. 100, p. 18-21, mar./abr. 1994.

RIBEIRO, Laís. Aplicação dos métodos estatísticos e da teoria da informação e da comunicação lingüística: estudo da linguagem jornalística. Ciência da Informação, Rio de Janeiro, v. 3, n. 2, p. 151-154, 1974.

ROSZAK, Theodore. O culto da informação. São Paulo : Brasiliense, 1988. $335 \mathrm{p}$.

SENNA, Ana; TAVARES, Marcia; HOLLANDA, Ricardo de; WEITZEL, Simone. Informar para democratizar : projeto de análise crítica do IBASE sob o enfoque da racionalidade instrumental no contexto informacional de uma ONG. Rio de Janeiro, 1991.49 p. Datilogra-fado. Trabalho apresentado ao curso Informação e Contexto Social, professora Regina Marteleto. Mestrado em Ciência da Informação convênio $\mathrm{CNPq} / \mathrm{IBICT}$ e UFRJ/ECO.

SOUZA, Herbert de. A estratégia da informação. Políticas Governamentais, Rio de Janeiro, v. 7, n. 67 , p. 22-24, mar./abr. 1991.

SOUZA, Herbert de. O pão nosso. In: REFLEXÕES para o futuro : edição especial comemorativa de aniversário 25 anos da Revista Veja. São Paulo : Abril, 1994. p. 14- 21.

SOUZA, Herbert de. O pão nosso. In: . SOUZA, Herbert de; RODRIGUES, Carla. Ética e cidadania. São Paulo : Moderna, 1994. p. 30-34.

Data do Recebimento: 16/05/2005

Data do aceite: 30/06/2005 